\section{ELECTRONICS SYMPOSIUM AND EXHIBITION}

$\mathrm{T}$ HE third electronics symposium organized by the Scientific Instrument Manufacturers Association was held in London during September 5-8. It followed the practice established last year in being accompanied by a compact, specialized exhibition of electronic instruments for use in research and industry.

The proceedings were officially opened by Sir Ben Lockspeiser, secretary of the Department of Scientific and Industrial Research; and the first address of the symposium was given by Prof. G. I. Finch, professor of applied physical chemistry, Imperial College of Science and Technology, London, who dealt with some industrial applications of electron optics. Prof. Finch pointed out that electron-optical methods have opened up wide new fields of experimental work for the study of surfaces and their properties. For the first time it has become possible to ascertain directly the nature of the atoms and their arrangement in surfaces, and also to map out surface texture to a detail approaching atomic dimensions. It would be difficult to exaggerate the importance to industrial problems of such a searching probe. Absorption, catalysis, crystal growth, adhesion, photo-electric and thermionic emission, mechanical wear and lubrication, corrosion and surface chemistry in general-all find their ultimate explanation in the atomic structure and texture of surfaces.

The succeeding sessions on September 6 were devoted to three papers on direct-current measuring and recording instruments. In the first, entitled "Recent Improvements in Direct Recording", W. Bamford (Everett, Edgcumbe and Co., Ltd.) described improvements in the driving movements of recorders in the directions of higher speeds of movingcoil elements, with better control of damping characteristics and the increase of facilities of the servo-operated types with their wide charts and multiple records. The limits of frequency response of direct recorders were discussed, and reference was made to a multi-pen pattern operated from a supersonic switching mechanism. Among marking devices, the improved ink-on-paper recorders and the latest details of electrical-discharge papers and their applications were described. The second paper was presented by R. Y. Parry and H. W. Finch (E. K. Cole, Ltd.) on the subject of the "Vibrating Reed Electrometer and its Application to the Measurement of Small Ionization Currents". This comprised a description of a simple vilurating condenser electrometer for measuring small direct currents and voltages under conditions of high impedance. The full-scale sensitivity of the instrument is $3 \times 10^{-14}$ amp. or $30 \mathrm{mV}$., and fluctuations of the zero correspond to about $10^{-15} \mathrm{amp}$. or $1 \mathrm{mV}$. from day to day under normal laboratory conditions. This paper was followed by one entitled "A Review of Trends in $p$ H-Meter Design", read by G. I. Hitchcox (Electronic Instruments, Ltd.), in which it was pointed out that the essential characteristics of any $p \mathrm{H}$-meter are very high input resistance, stability and reliability under unusually severe industrial conditions. Further, it must be borne in mind that these instru. ments are usually operated by engineers from other fields, who may be unacquainted with electronics and often sceptical of the reliability of such apparatus. The paper concluded with a description of the practical difficulties which follow the use, for reasons of economy, of ordinary commercial components ; and some means were suggested for overcoming or minimizing these difficulties.

The morning session of September 7 opened with a paper on "Some Aspects of Electronic Counting", by J. McG. Sowerby (Cinema-Television, Ltd.), in which a variety of electronic counter circuits was described beginning with a scale of two. It was shown how ring counters can be derived from the scale of two, and how counters of any scaling factor-including large prime numbers-may be constructed from more elementary circuits. Applications of these circuits to frequency division, the measurement of short time intervals, and the measurement of frequency were also described. This was followed by an interesting paper entitled "The Beta-Ray Thickness Gauge and its Industrial Applications" by G. Syke (Baldwin Instrument Co., Ltd.). The author referred to the fact that, in numerous industrial processes, it is essential to gauge the thickness or weight per unit area of sheets, strips and films, which may be moving at high speed. Radioactive isotopes from the atomic pile at Harwell emit ionizing radiations which are progressively absorbed, or attenuated, in passing through matter. The ratio of transmitted to incident radiation is a function of the quantity of matter traversed. This ratio can be accurately measured by simple electronic instruments, which are calibrated in terms of weight per unit area $\left(\mathrm{gm} . / \mathrm{m} .{ }^{2}, \mathrm{mgm} . / \mathrm{cm} .{ }^{2}\right.$ or $1 \mathrm{~b} . / \mathrm{sq}$. yd.) or directly in terms of thirkness for any material of a given density. In addition, a balance indicator shows the deviation from a preset weight or thickness. The electrical output of the instrument is sufficient to drive recorders or servo-mechanisms for automatic process control. Applications to textile, paper, rubber, plastic, motal and other industries were described and illustrated. Trends of development, for example, gamma-rays for gauging heavy metals of considerable thickness, were indicated.

It was appropriate that the final paper of the symposium, given by J. K. Brimley (Nobel Division, Imperial Chemical Industries, Ltd.), should deal with the subject from the point of view of the user of instruments, and particularly in relation to the application of such instruments to industrial conditions. Mr. Brimley emphasized the fact that electronic instruments intended for use in industry must be designed for factory, and not laboratory, conditions; and it is important to bear in mind the actual physical conditions under which it will be necessary to use the instruments. There are also some considerable maintenance problems experienced by industrial users, for in many cases such muin. tenance has to be carried out by staff not possessing high technical qualifications. It is therefore essential that the greatest possible simplicity in design should be achieved, both from the electrical and the mechanical points of view. More rapid progress in the production of an instrument for some new application would, in general, be made if the designer and the user collaborated closely during the whole of the design stage.

In the exhibition some twenty member firms of the Scientific Instrument Manufacturers Association Eloctronics Group showed a variety of instruments and associated items; and it was evident from the display that scientific instrument manufacturers are continually extending and improving the applications of electronic techniques in instrumentation. A considerable field of application of electronic devices has 
been opened up in connexion with methods of counting the fundamental particles of Nature, and in problems relating to radioactivity in general; several instruments for such purposes were exhibited. The widening needs of the radio engineer were also catered for in such items as standard-signal generators, field-intensity meters, valve voltmeters and oscil. lators of various types. The influence of television and frequency-modulation broadcasting has resulted in the production of a television sweep generator covering the frequency-range 40-190 Mc./s., a frequency-modulation receiver tester for the range 21-168 Mc./s., and also a carrier-deviation meter having a signal carrier range of 4-250 Mc./s., with deviation ranges of $0-5,0-25$ and $0-75 \mathrm{kc} . / \mathrm{s}$. The continued success and popularity of this symposium and exhibition should do much to assist the development and application of electronic techniques of all types.

\section{THE BRITISH HAT AND ALLIED FELTMAKERS RESEARCH ASSOCIATION}

\author{
By DR. T. BARR \\ Director of Research
}

$\mathrm{F}^{\mathrm{T}}$ LTMAKING as a textile industry preceded the manufacture of woven fabrics. In England, it has been an established craft for some centuries, with the Worshipful Company of the Art or Mistery of Feltmakers, a Livery Company of the City of London, controlling its destiny. This Company was granted its first Royal Charter in 1604 ; but records show that the industry was in existence for at least a hundred and fifty years prior to that date. With such a traditional background, there has been a natural reluctance to change. In addition to this aversion to change, the feltmaker, until recently, has closely guarded his secrets and processes from his neighbour, who was virtually his only competitor.

The pressure of outside events, however, has resulted in a revolution of ideas within the industry, culminating in the formation of the British Hat and Allied Feltmakers Research Association, the laboratories and headquarters of which at Stanley House, Fairfield, Manchester, were formally opened on September 19 by the Earl of Derby.

The change in the attitude of the industry which led to co-operation in the solving of its common problems was clearly expressed by Col. J. A. ChristieMiller (president of the British Felt Hat Manufacturers' Federation), who said : "As a result of two world wars, the opening of new factories in many countries, the installation of new machinery which is largely automatic and does not require skilled men to work it, and because of trade barriers and import restrictions, our competitors to-day are largely overseas." He pointed out that the industry's roughand-ready methods are no longer adequate if it is to compete in world markets. It must make the fullest use of the scientific knowledge available and apply it to meet the specialized needs of the industry.

Attempts to form a research association for the hat and felt industry date back some thirty years; but it was not until 1943 that any real interest was displayed. Then the efforts made by a small research committee of the Worshipful Company of Feltmakers resulted in laying the foundations for the present organization. The response by firms engaged in the industry surprised even the sponsors of the scheme, whose hopes at the most were centred on securing enough funds to promote one or two research projects in existing laboratories. Once the benefits to be derived from the application of scientific methods in solving the long-standing technical problems of hat and felt manufacture had been appreciated, sufficient support was received from various branches of the industry and associated trades, and it was found possible to make immediate plans for establishing a felt research centre.

The Research Association was incorporated in February 1947, and recognized by the Department of Scientific and Industrial Research shortly after, being given the same status as other similar organizations with a substantial grant from Government funds, based on the income derived from the industry. In the same year, the first technical appointment was made, and the work of equipping laboratories and initiating a research programme was begun. Experimental work was started in 1948 in temporary quarters in the University of Leeds, where a laboratory was rented from the Department of Textile Industries. Although space was limited, the freedom to use the equipment and library facilities available at the University was of inestimable value in the early days of the Association while a permanent home was being found and equipped.

The research programme of the Association is decided and controlled by three research committees, representing the three main sections of the industry, producing wool felt, fur felt and hatters' fur respectively.

The initial programme took full cognizance of the fact that the industry, having developed by empiricism and reliance on rule-of thumb methods, was lacking in quantitative methods of assessing progress. Therefore, the physical properties of felt are being studied in the hope that tests will be evolved as yardsticks for the trade. Arising from this study, a scheme for the quality control of felt has already been worked out which separates 'bulk' properties from 'fibre' properties. This scheme has found many applications and has provided members of the Association with the means of measuring changes in the quality of felt resulting from the modification of manufacturing procedure; and at the $\operatorname{sam} \theta$ time it has made it possible to determine whether or not the fibres from which the felt is manufactured have undergone any degradation during processing. In measuring the tensile properties of the felt, which forms an essential part of the scheme, it was discovered that the shape of the load-extension curves of the test samples is related to the previous history of the felt. The full significance of this discovery is demonstrated by the fact that it has repeatedly been used for solving 'blocking' problems of hat manufacturers.

The research projects also include studies such as that of the 'carrotting' process-the preparatory chemical treatment for rabbit and other furs, without which they lack the requisite properties for felt manufacture. A fundamental study of carrotting was begun in order to elucidate the chemistry of the reactions and the mechanism of the changed felting properties arising from the treatment. Considerable advances have already been made in this line of research. and 